\title{
London's population
}

\author{
Pablo Mateos
}

\section{Introduction}

A city is defined by its population: the number of inhabitants, their demographic characteristics and geographical distribution. Indeed, demography is key for planning a city's future, since the current and future number of people per age, sex and ethnic group and geographical area of residence determines all dimensions of urban life, from economic, health, education, fiscal, housing or transport policies to many other socio-cultural aspects. However, forecasting a city's demographic future is an extremely difficult undertaking, as will be discussed in this chapter. It is an endeavour that requires 'a mirror to the past and the crystal ball to the future'. This chapter will dive into London's population historical facts, to then adventure into possible future trends over the coming decades.

London's population size during the last two centuries has experienced quite a bumpy ride. At the very first Census of Population, in 1801, just 1.09 million people were enumerated within the current geographical boundary of Greater London. Throughout the nineteenth century London's population increased six-fold to 6.5 million in 1901. This trend continued up to the beginning of the Second World War, reaching the largest population size that London has ever had; 8.6 million in 1939. The war actually marked the outset of five decades of continuous population decline, as a result of post-war reconstruction, slum clearance, suburbanisation, the 'green belt' restriction on sprawl, de-industrialisation, a decline in fertility rates and smaller household sizes. As a result, in 1991 London's population had been reduced to 6.4 million people, less people than it had at the start of the $20^{\text {th }}$ century. Since then, trends in population decline have reversed. Through processes of international migration, urban renewal, a sustained economic boom, and a recent rise in fertility rates, London has grown over the past two decades to reach 8.17 million in 2011, its former size in 1931.

This story summarised in a total people headcount actually hides a range of very different population dynamics that will be teased out throughout this chapter. The most classic of such dynamics is geographical differentiation, or a tale of two different Londons: Inner and Outer London. Figure 1 shows that the total population of Inner London boroughs actually peaked around 1911 at just above

\section{How to cite this book chapter:}

Mateos, P. 2013. London's Population. In: Bell, S and Paskins, J. (eds.) Imagining the Future City: London 2062. Pp. 7-21. London: Ubiquity Press. DOI: http://dx.doi.org/10.5334/bag.a 


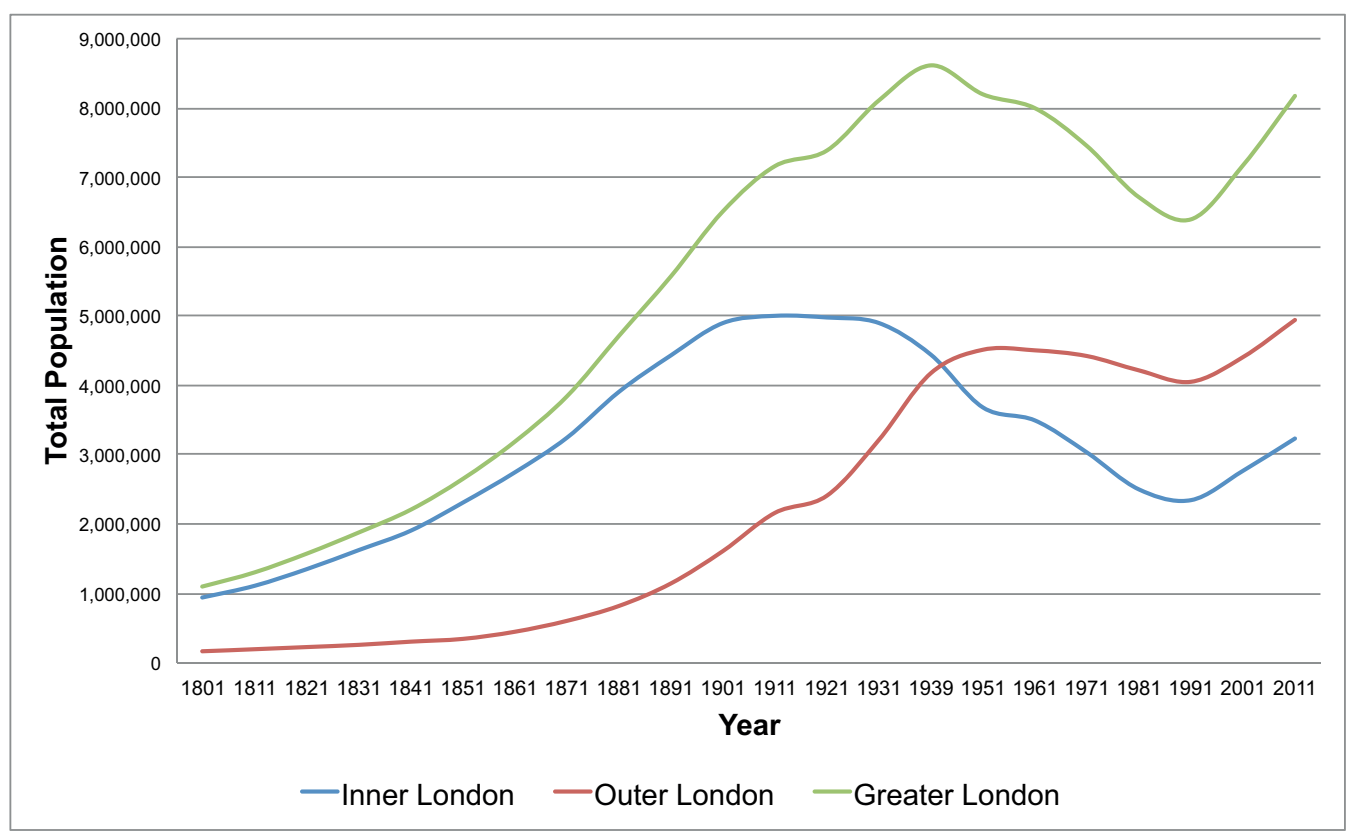

Figure 1: Inner and Outer London's total population (1801-2011) (Greater London Authority, 2012). The top line (Greater London) shows the combined total population of Inner and Outer London, which also appear as individual line graphs below it.

five million people, a point from which it continuously lost population throughout most of the $20^{\text {th }}$ century, halving to 2.3 million in 1991. However, over the last two decades it has gained almost 0.9 million people, averaging 1.6\% growth per year, reaching 3.2 million in 2011. Meanwhile, Outer London population only peaked in 1961 at 4.5 million, surpassing Inner London by one million at the time, and signalling the end of a long process of suburbanisation that started in the 1870 s and 80s with the expansion of the suburban railways and the underground system. Between 1961 and 1991, Outer London lost half a million people, mostly due to de-industrialisation, but since then it has added another million people (a growth averaging 1\% per year), reaching 4.9 million in 2011.

The main driver of population growth over the last two decades has been international migration, although since the late 2000s the largest component is actually natural change: the difference between births and deaths. This is due to London's extremely young population structure, compared to the rest of the UK. However, London's total population figure is far from being a stable mass of people, but instead reflects the net sum of a set of complex in and out flows bringing in vast amounts of young people in their 20s and 30s from the rest of the UK and the world, who typically have children in London and then emigrate outside London either as young families in their mid-to-late 30s, or at post-retirement ages. Such a demographic state of flux basically pertains to three types of events at the individual and household level; where and when people move, have children and die. This chapter reviews the factors and key trends behind such demographic events, and how they may shape up the peopling of London in 2062.

\section{Inequalities in life and death: natural change}

The two obvious defining factors in a person's life are its beginning and its end, or a birth and a death. Indeed, where and when these two events occur, summed over everyone, have important consequences for the population size of any city, region or country. The difference between the 


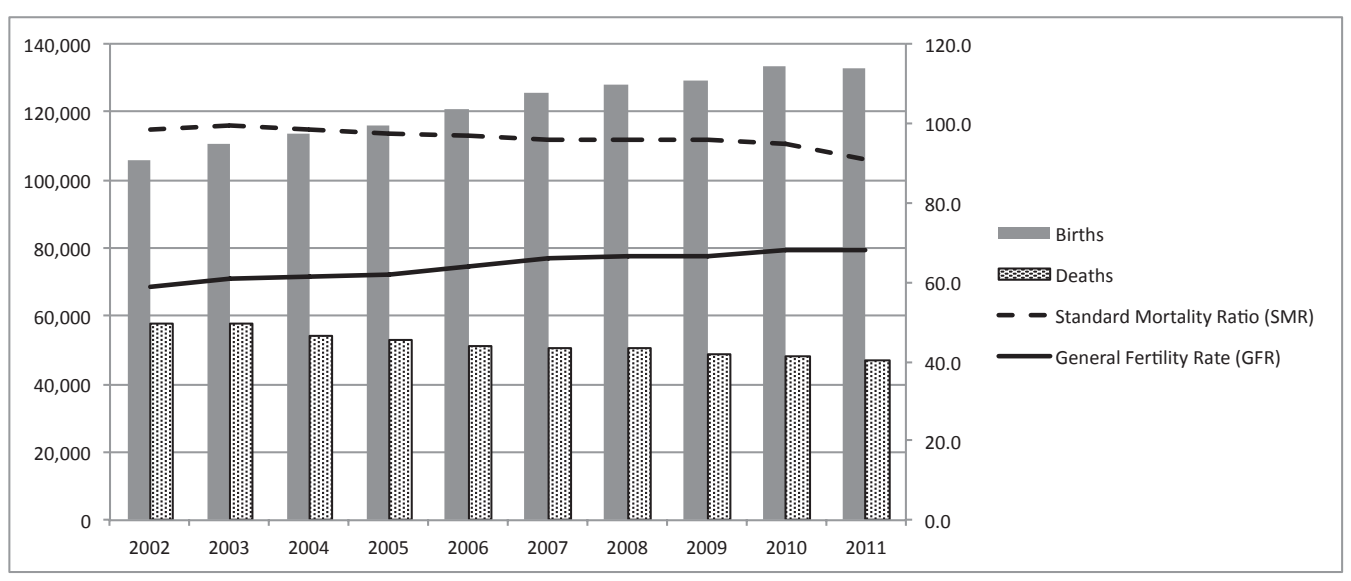

Figure 2: Evolution of natural change, fertility and mortality (2002-2011) (Greater London Authority, 2011; 2012).

dates of these two events, calculated over a person's life and averaged out across a whole population, gives us its life expectancy. Calculated over a city, region or country, the difference between the number of people being born and those dying over a particular time period (normally a year), gives us its natural change.

However, for most inhabitants of London, both life events rarely happen within Greater London's boundary, hence the life expectancy of Londoners is a summary of health conditions and demographic characteristics of populations across the globe. Although many people are indeed born in London, they are highly likely to emigrate as children before school age. At the other end of the life cycle, many Londoners are also likely to emigrate after retirement or reaching older ages, hence dying outside London despite having spent a lifetime there. This all means that figures on the life expectancy of Londoners are obviously problematic, since they are calculated from vital statistics (births and deaths registers) drawn within the Greater London boundary. This means that when talking about London's populace, we are never referring to a closed or static population, but one comprised of constantly changing membership. With this caveat in mind we will now review some of those vital statistics and life expectancy trends in London.

Because of London's imbalanced age-migration profiles, which will be discussed in the following section, London's natural change is widely positive. In other words, there are more children being born than people dying in any particular year within London's boundary. In 2011 natural change accounted for an increase of 86,158 people (Greater London Authority, 2011), the difference between 132,843 births minus 46,685 deaths. As indicated in Figure 2, this difference has been steadily increasing over the last decade. This is primarily a result of a surge in the number of births, derived from a growing and young population, but also because of a slight decrease in the number of deaths. The latter could be caused by selective emigration rates of older people with health issues that result in 'premature' mortality elsewhere, whilst boosting London's overall life expectancy. As a result of these trends, and because of a stabilization or reduction in net migration rates (the difference between immigration and emigration), natural change has become the main driver of population growth in London over the last five years (2007-2012).

\section{Fertility}

Figure 2 also shows that such a steady increase in fertility is not only due to a larger and younger population, but also to an increase in relative fertility rates. The general fertility rate (GFR) used 
in the figure, is the annual number of live births per 1,000 women of childbearing age (aged 15 to 44). Between 2002 and 2011 the GFR has increased from 58.6 to 67.8, or nearly ten births per 1000 women of childbearing age. The Total Fertility Rate (TFR) is the number of live births per woman at the end of her reproductive life, if her childbearing at each age reflected current age-specific fertility rates. The TFR for London went from 1.29 children per woman in 2001 to 2.0 in 2010, after which it dropped to 1.84 in 2011 (Greater London Authority, 2012). Such increase in fertility rates is the combined result of several processes of population change: postponement, migration and ethnicity.

Postponement refers to the well-known trend of postponing childbearing to older ages. When an entire generation postpones the birth of a first child five to ten years compared to their parents' generation, this has a substantial impact on annual fertility rates when summed over the whole population. Such impact is known in demography as the tempo effect, or a transition between two different fertility regimes (Bongaarts \& Feeney, 1998). If at the end of a woman's reproductive age, she and her cohort (those born in the same year) have had the same number of children as her mother did, there is no overall fertility decline (cohort fertility). However, motherhood postponement is likely to be noticed in any given time period. Part of the very low TFR rates in London in the late 1990s and early 2000s were actually caused by this transitory tempo effect, combined with emigration.

Furthermore, migration and ethnicity have also had an impact on London's fertility. Migrants tend to be younger and hence are more likely to have children than natives, which contributed to an increase in the absolute number of children born in London during the 2000s. Finally, some socioeconomic groups (the poorest and the very well off) as well as some ethnic minority groups, have slightly higher fertility rates than the average population. However, it has been demonstrated that ethnic minorities' fertility rates tend to level off with the general population very rapidly soon after migration (Coleman \& Dubuc, 2010). London's national share of ethnic minorities, the very affluent and the very poor has increased over the last decade and this has probably had a small impact on its TFR over this period. In any case it is important to remember that many women do not actually spend their whole childbearing age in London. Therefore, it is difficult to extrapolate annual TFRs from actual childbearing behaviour of women who have not reached the end of their reproductive age and are currently residing in London.

Furthermore, fertility rates vary enormously across London. The TFR reaches 2.87 children per woman in Newham and the more deprived parts of Eastern London, while falling to just 1.18 in Westminster, a difference of more than a child 'and a half' per woman. Differences at smaller neighbourhood scales are probably much higher, although the TFR is not available below the borough (local authority) level.

\section{Mortality}

Unequal mortality patterns across London have been a key characteristic of the city at least since John Graunt, probably the first demographer in history, studied them in the $17^{\text {th }}$ century in his 'Bills of Mortality' (Graunt, 1665). One of the most commonly-used measures of mortality is the Standard Mortality Ratio (SMR). The SMR measures whether the population of an area has a higher or lower number of deaths than expected, based on the age profile of the population, compared to a national average or standard population. The SMR is expressed as a ratio with a base of 100. An SMR above 100 implies that there is 'excess mortality' whereas one below 100 suggests below-average mortality. London's SMR has declined from 98.5 in 2002 (i.e. close to the UK average of 100) to 90.9 in 2011, indicating a much lower mortality ratio than the overall UK population.

Life expectancy at birth in London in 2010 is 83.3 years for females and 79 for males (Office for National Statistics, 2011), slightly higher than for the whole of the UK; 82.3 and 78.2 respectively. This difference with the national average is attributed to entrenched wealth and health differences 
across the country, with London being more affluent and hence its population living slightly longer. However, this difference is also a consequence of selective outmigration of less healthy and older Londoners in middle and elderly ages, moving closer to their families or to affordable retirement destinations, and hence more likely to die 'earlier' and outside of London than more healthy Londoners who stay put. As a result, at age 65, life expectancy in London is 21.5 years for females and 18.7 for males. This means that those who have made it to 65 will live on average to 86.5 in the case of females and 83.7 in males. However, these average figures actually disguise startling geographical variations across London's unequal neighbourhoods. A commonly repeated illustration of such inequalities is that moving east on the underground along the Jubilee line, life expectancy between the boroughs of Westminster and Tower Hamlets drops at an average rate of 1 year of life per underground station (Atkinson, 2006). Figure 3 reproduces a popular map of such stark differences in life expectancy around each underground station in central London published by UCL Centre for Advanced Spatial Analysis (CASA) (Cheshire, 2012). Using this map's metrics to assign neighbourhood life expectancy (at birth) to each underground station, the starker and closest contrast happens to be on the Victoria line. Moving from Oxford Circus, with life expectancy of 96 years, just one stop to Warren Street, very near University College London (UCL), life expectancy drops to 79. A whole 17 years of life removed from populations neighbouring just 800 metres, or the same number of years as the difference between Japan and Bangladesh's life expectancies. Other stark contrasts appear in the inner-London section of the map reproduced in Figure 3 but many more are included in the full on-line version of this map, such as the clearly-indicated north south-divide.

Despite these favourable mortality trends, London's population is far from being considered healthy in terms of morbidity (prevalence of disease). Paralleling the aforementioned geographical disparities in life expectancy, some London boroughs actually present the starkest health inequalities in the country. Furthermore, London as a whole falls behind other large UK cities in many public health indicators. For example in low birth-weight babies, teenage conceptions, childhood obesity, childhood immunisations, chlamydia infection, HIV prevalence, incidence of tuberculosis, mental health, decayed teeth, or heart disease and strokes (Baker et al, 2012). Some of these 'less healthy' Londoners actually move out of London in middle age or after retirement, to perhaps find an early death somewhere else, hence contributing to 'improving' London's overall mortality figures. Despite their importance for people's quality of life, it is not the purpose of this chapter to discuss wider health and wellbeing issues, unless these have an effect on demographic trends.

\section{London's revolving doors: migration}

With respect to migration, London comprises a unique 'demographic laboratory', only found in a few other world cities. It is characterised by a very high population turn-over rate, a phenomenon we call 'London's revolving doors'. Every year around 9\% of its population moves into London while close to 7\% leaves its territory. In 2011 alone the total number of in-movers and leavers added up to 1.3 million. Put in other terms, during the ten year period 2002-2011, a total of 7.3 million inflows and six million outflows took place (Greater London Authority Intelligence Unit, 2012). In a city of 8.1 million inhabitants in 2011, such a high population turnover rate has dramatic implications on a number of fronts. Evidently, some of these distinct flows will be generated by the same individuals coming and going, and thus being counted multiple times. However, it is very likely that a substantial amount of them are unique person-moves within the decade, meaning that a significant proportion of London's population is replaced within a decade. The most striking consequence of these revolving doors is how fragile the overall balance of population actually is, and it is surprising how little it is discussed in public debates. Let us untangle what makes London's doors revolve. 

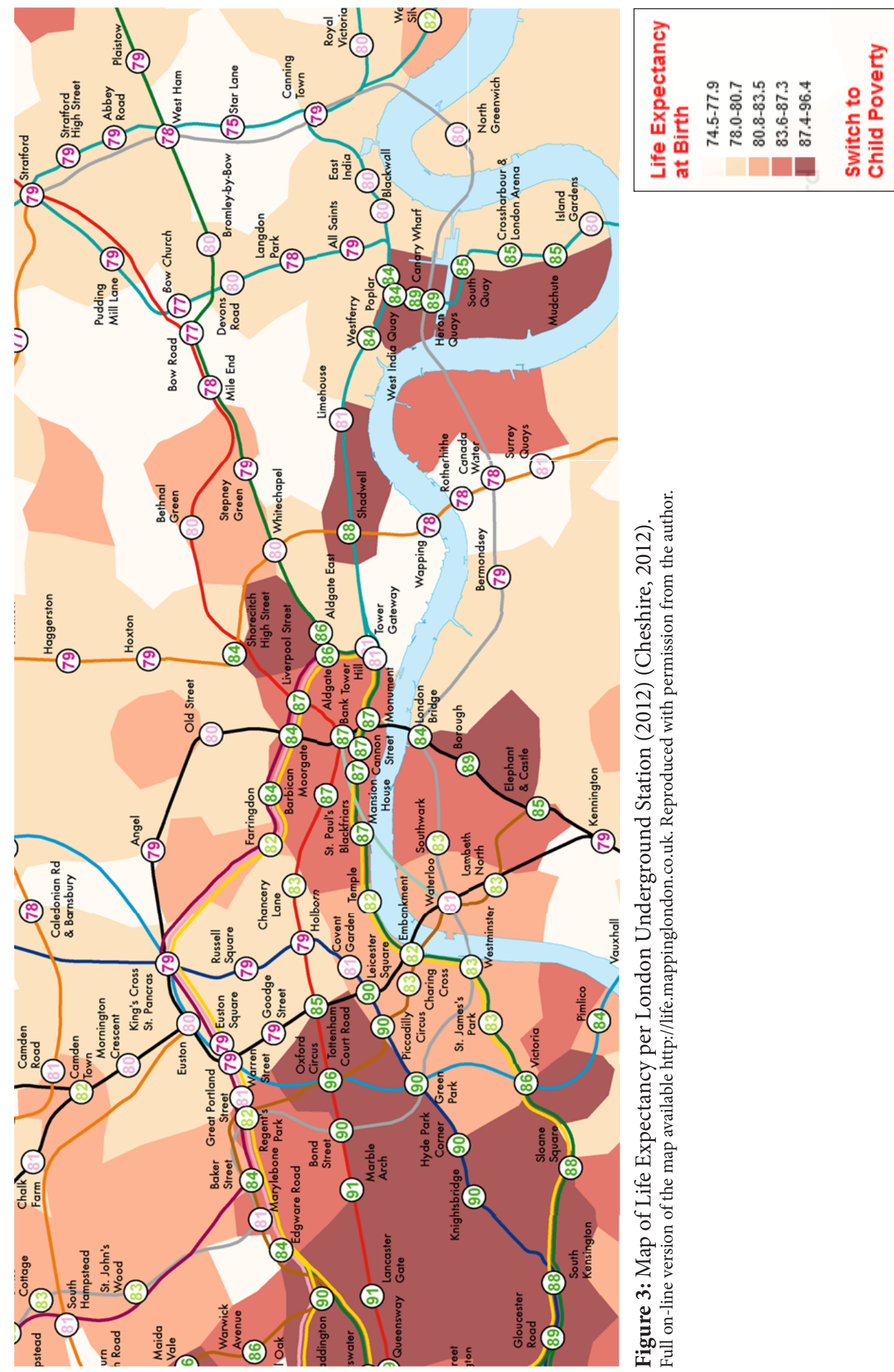

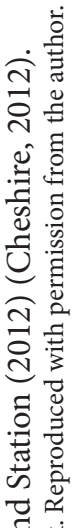
긍 它蓠 气ี :

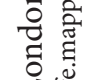
灾.

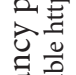
콘

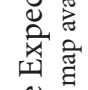
$\dddot{\exists}$ पु 究 $\ddot{m}$ 这 器新 


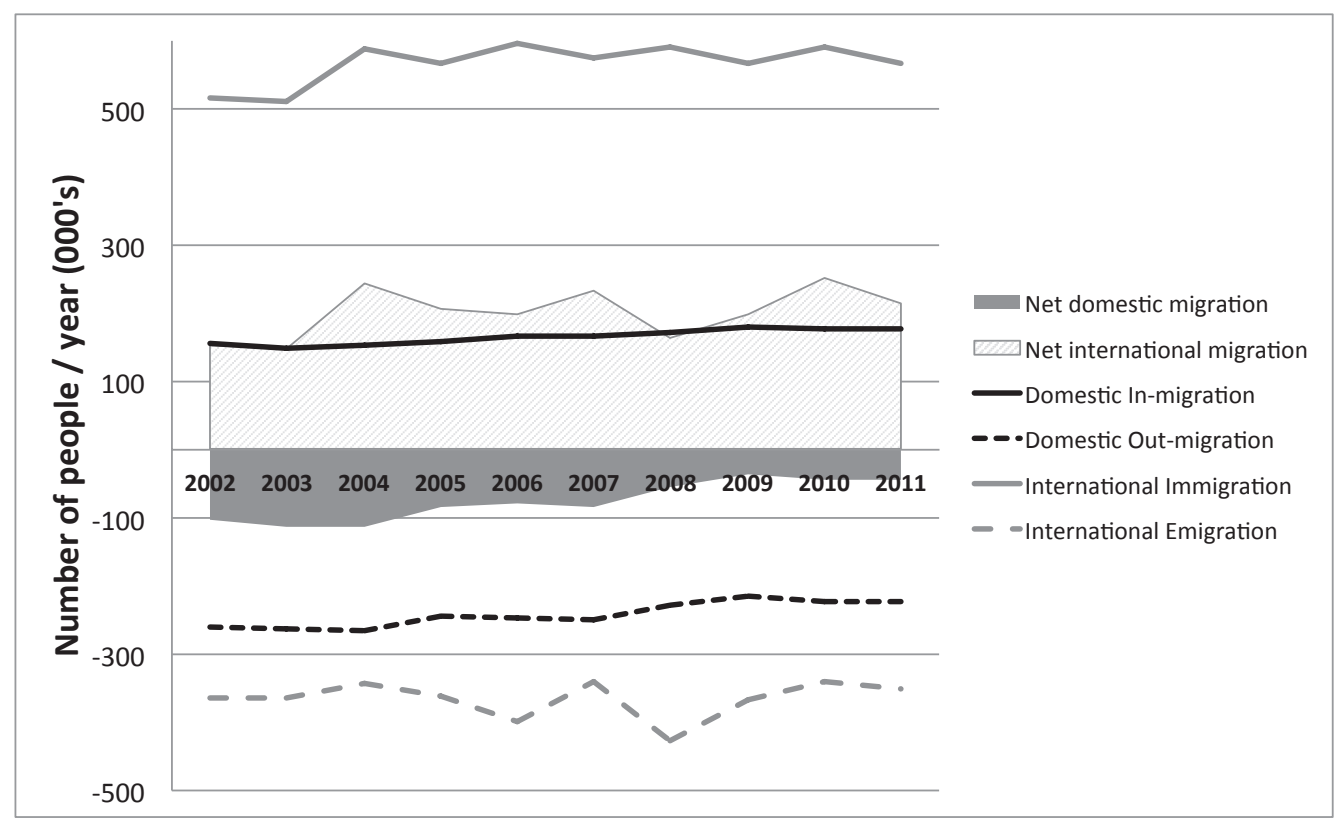

Figure 4: London migration flows (2002-2011) (Greater London Authority Intelligence Unit, 2012).

Migration is the third demographic driver in any population, together with births and deaths. Over the last decades London has been widely conceived as a city of immigrants, drawn both internationally and domestically. However, the absolute number of migrants added to any population (also termed 'stock') is necessarily the net difference of people moving in minus people moving out. This concept is termed net migration, and for a city like London it is actually calculated adding four distinct gross flows: two domestic migration flows (out- and in-migration from/ to the rest of the country), and two international flows (immigration and emigration from/to the rest of the world). The difference between the former pair is known as net domestic migration while that between the latter; net international migration. Despite the fact that these four flows are largely independent of one other, they together determine London's fragile population balance. Figure 4 shows how this balance has been sustained over the last decade, breaking down the four gross flows and the two net migration components for London. It is therefore very important to tease out the underlying factors driving each of these four gross flows in order to understand their impact on the two net migration components. The key explanatory driver of these migration flows is their age profiles.

In net terms, the key characteristic of London's migration system is a city that draws in massive numbers of people in their 20s without children, and tends to expel everyone else. Figure 5 shows the age profile of inflows and outflows in 2009. We observe two interesting phenomena that form part of the same 'revolving doors' balance. First, London as a whole loses population in all age groups except the 20-29 age group (the only one showing a positive net migration rate). Second, two age groups present a higher negative net migration rate: a) children aged $0-4$, and their parents in the late 30s and early 40s, representing young families seeking more space and better schools before children reach school age b) people aged 60-64 and 75 and older, respectively representing near-retirement and later-life out-moves. Finally, if we calculate the ratio of outflows to inflows for each 5-year age group, we find that there are twice or more outflows than inflows between ages 0-14 and 55-75+. This fact clearly reveals London's 'expulsion' of less economically active populations. In other words, London acts primarily as a city for work, where all other aspects of the lifecourse are hard to sustain. 


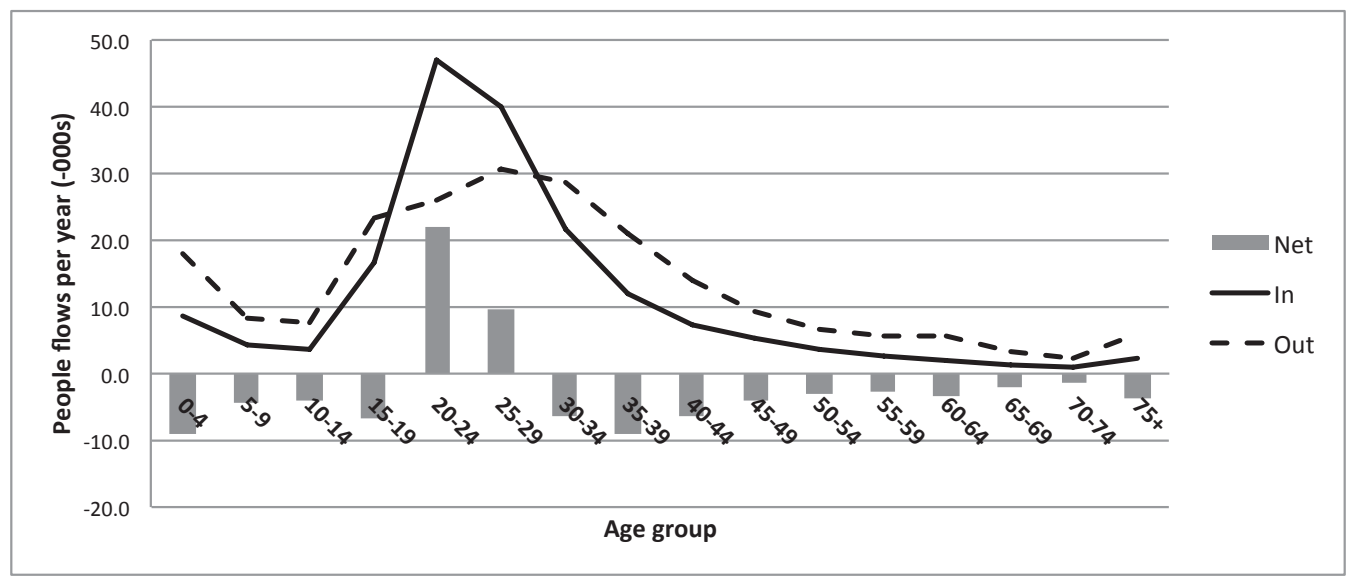

Figure 5: London migration flows by age group (2009) (Greater London Authority Intelligence Unit, 2012).

Geographically, these moves take place over a range of distances. Domestically, London net migration flows are positive with all UK sending-regions except the East, South East and Southwest Government Office Regions (GORs). London actually loses population to these three GORs which are within commuting distance of London. Overall, London draws in large numbers of young people at university-entry or job-entry ages from all of the UK, who mostly leave London in their 30s or at retirement for the South-East regions. In Figure 4 we can clearly see that domestic net migration in London has been negative for the whole of the previous decade, although the absolute number has declined, especially since the outset of the recession in 2007-2008.

Internationally, the situation is too complex to summarise here, but we know from Census data that age profiles of immigrant inflows to London are slightly older than UK-born in-migrants (mostly in their late 20s to early 40s) and that they tend to emigrate to other countries and not to other UK regions. Furthermore, were it not for sustained positive international net migration flows averaging 200,000 people per year (2002-2011), London would have lost population very rapidly over the last decade. Figure 4 shows that net international migration is actually driven by fluctuations in emigration flows and not so much in immigration flows. Furthermore, unlike in other UK regions, immigration flows into London have largely been sustained at pre-recession levels. Emigration flows increased slightly in 2008, at the beginning of the recession, but have gone back to previous levels since then. Understanding the nature of such emigration and immigration flows' fluctuations is even more complex, since over 220 countries are involved and international migrants also include British nationals (those 'coming back' to the UK as well as native emigrants or naturalised migrants 'going back' to other countries).

The reasons behind decisions to move in and out of London depend not only on perceptions of labour opportunities, housing, or education prospects in London and the rest of the UK, but how these compare to those available worldwide. These factors are of course intersected with a person's and household's life-stage, family formation and housing cycles, as well as other socio-economic and cultural factors. Will London's revolving doors keep churning people at such high velocity over the next decades? What if one or several of these four types of migration flows changes drastically? Will the city be able to sustain its economic and cultural vibrancy without a vast incorporation of international immigrants arriving in their 20 s and 30 s who feed in and counterbalance the erosion in the rest of the demographic system? Will this fragile balance of demographic events that keeps London's population thriving be sustained in the future? These are crucial but mostly overlooked questions when talking about London's population. 


\section{How many Londoners in 2062? Forecasting population trends}

Existing demographic forecasts produced by different agencies all predict that London's population will increase over the next decades, reaching between nine and ten million residents at some point between 2030 and the middle of the $21^{\text {st }}$ century. However, these projections rely on a myriad of assumptions, most of them too difficult to predict over long periods of time. They have to do with the reasons behind decisions on when and where people decide to move or to have children, not just in London but in the rest of the UK and especially around the world. However, current population growth trends can revert quickly with just a slight change in one of the demographic elements sustaining London's overall population balance, as we have seen in the recent past.

Population projections are necessarily based upon assumptions about the future behaviour of each of the three demographic drivers: fertility, mortality and migration. Out of these three, the easiest to predict is future mortality rates. Improvements in life expectancy and morbidity rates have been fairly stable for most age groups. Furthermore, the majority of the base population to which these mortality rates will be applied has already been born. This means that it can be mechanically 'aged', one year every year, applying agreed mortality rates to each age group. However, fertility rates are much more difficult to predict, although not as problematic as migration rates. Future fertility rates are based on the predicted total fertility rate (TFR) broken down per age group (sometimes also by ethnic group). Therefore, fertility forecasts are based on two aspects: on the one hand, the projected age and gender population structure; and on the other, on predictions about decisions on when and how many children women in childbearing ages will have. The latter is extremely difficult to predict, since past fertility trends cannot be linearly projected into the future, because they concern a host of economic, cultural, lifestyle, and other social factors about the people now alive as well as others to come. Will childbearing postponement trends revert in the future? Will London sustain recent increases in the TFR close to replacement rates or will it go back to extremely low levels such as the 1.3 children per woman of the early 2000s? Will advances in assisted reproduction techniques allow older women to become mothers, and will the generalised use of these techniques substantially increase the already high number of multiple births in London? Demographers can only do some guesswork based on expert opinions and observe historic cycles, averaging out future trends into a single TFR for a range of years wrapping a bracket of confidence intervals around it.

As we have seen in this chapter, migration is the key driver in London's population and does in fact control the dynamics of the other two demographic factors. Predicting whether London will keep attracting a large number of young people from the rest of the UK and the rest of world is more of an art than a science. Apart from maintaining the economic, entertainment and lifestyle attraction of the city, there needs to be enough affordable housing for everyone, a transport system able to cope with an increasing number of journeys, as well as other public infrastructure such as accessible schools and healthcare facilities wherever population increases. Given the slow pace at which such infrastructure is created, the lack of space and an aversion for higher population densities, it is difficult to foresee where an expanding number of Londoners will live. Furthermore, future political scenarios of the UK leaving the European Union or the single market, or if it stays, the prospect of further EU expansions, will definitely have an impact in London's migration as we have seen in the 2000s. However, net migration is not only driven by people moving in, but also those moving out. If the current positive net migration rate for the 20-29 age bracket (seeFigure 5: London migration flows by age group (2009) (Greater London Authority Intelligence Unit, 2012). 5 ) is substantially eroded by a higher number of out-migrants in that group, the net migration figure for the whole of London might come close to a neutral or negative rate. In fact, various population projections seem to predict the latter scenario (see Figure 6). Finally, predictions on migration rates tend to be probabilistic, by including a set of future migration scenarios of high 


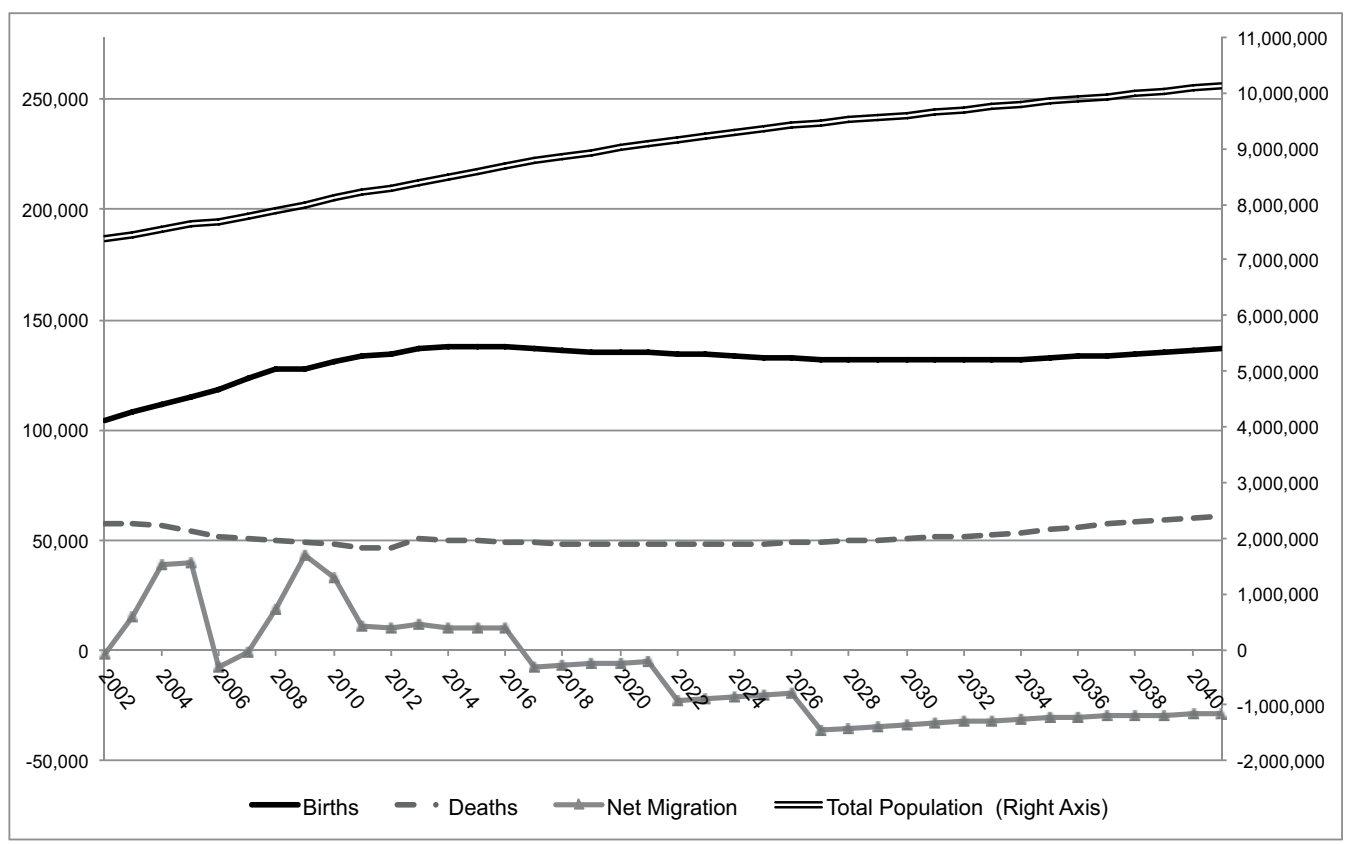

Figure 6: GLA London population projection 2002-2041 (Greater London Authority, 2012).

The three demographic drivers (births, deaths and migration) are represented on the left $y$-axis, while the resulting total population in the right $\mathrm{y}$-axis.

and low migration phases, each of which is assigned a probability. Therefore, final population forecasts will have a buffer of confidence intervals delimited by such upper and lower brackets within set probability levels.

A more refined type of population forecasting model takes into account the overall housing supply available in the city each year, so that the total population projected for each period is constrained by it. These models need to add a further assumption on the future household and/ or dwelling size, in order to convert housing stock to total population. The number of persons per household in London increased from 2.3 in 2001 to 2.5 in 2011 (2.4 in in England and Wales), contravening a trend for smaller households in most of the developed world for the last decades. One plausible explanation is London's rapidly rising housing costs, which may be forcing more people to share dwellings or stay longer with parents, although this hypothesis needs testing with longitudinal data. In Figure 6 a housing-constrained forecast is shown, produced by the Greater London Authority (GLA) in 2012 for the period 2011-2041, as well as showing past population trends. In this forecast we see the population of London increasing to ten million people by 2041, despite the net migration rate being negative from 2017-2041. One of the reasons why net migration is negative in this forecast is precisely because the housing supply cannot be increased fast enough to cope with natural population growth. However, whether the timing of those births will happen before or after out-migration from London is a tricky question that brings us back full circle, showing the circularity and interdependence between the three demographic drivers.

Finally, most population forecasts are built with projections focussed on a 25-30 year horizon, roughly one generation ahead. Beyond 2041 and onto 2062, the science of predicting the population of London starts to become science fiction, since the number of unknowns outweighs what we can realistically control for. As we have seen in this chapter, a great share of the population of London turns over within a decade, and therefore very few Londoners are alive today who will still be residents in 2062. The domain of science fiction does indeed bring interesting scenarios on how London could look in the future. Assuming an extremely low fertility scenario 
(zero births) and high immigration, the movie Children of Men (directed by Alfonso Cuarón in 2006 and featuring Clive Owen, Julianne Moore and Michael Caine) presents an unsettling urban dystopia for London in 2027, reminding us of the power of demography when thinking about cities' futures.

\section{A diverse population}

As a result of the aforementioned demographic processes, London is more 'ethno-culturally' diverse than any other Government Region or urban area in the rest of the UK, and probably than any other time in the city's history. The 2011 Census presents a unique opportunity to study ethnic and cultural diversity in the UK, since it comprises one of the few censuses in the world measuring a broad range of diversity dimensions (Mateos, 2014). As many as ten different Census questions are available relating to different aspects of these dimensions: country of birth, ethnic group, national identity, passport-citizenship/s held, religion, language/s most often spoken at home, English language proficiency, place of residence a year before the Census, year of arrival to country, and intended length of stay. Only some of the key trends in these variables will be summarised here, without cross-tabulating data between them (unless otherwise specified, all data in this section is taken from the Office for National Statistics, 2012). For more details on these questions for London, the reader is referred to the London Data Store resource (Office for National Statistics, 2012).

London is unquestionably the most ethnically-diverse area of the UK. In $201155 \%$ of London's population was not White British (19.5\% in England and Wales, hereafter E\&W), rising from $40.2 \%$ in London in 2001. This share of the population is comprised of many different ethnic groups, and although 'Non-White' groups tend to get all the media and academic attention, actually $15 \%$ of London's population belong to White groups different to White British (which itself includes all Whites with a UK national or identity adscription).

Looking just at immigrants, defined as those born outside the UK, these comprised $36.7 \%$ of London's population in 2011 (13.4\% in E\&W). If London was a country on its own, this would represent one of the highest relative migrant stocks in the world. Excluding city-states and small islands, only Israel, Jordan, Luxembourg and the United Arab Emirates have higher relative migration stocks than London. $48.2 \%$ of these immigrants had arrived in the UK within the ten years prior to the Census (2001-2011), while the rest have been living in the UK for longer. Therefore, roughly half of London's immigrants are recent migrants. Furthermore, $21 \%$ of Londoners have a non-British passport (7.4\% in E\&W), and 3.1\% of Londoners have multiple passports $(1.1 \%$ in $\mathrm{E} \& \mathrm{~W})$. The difference between the number of migrants born abroad and those without British passports is accounted for by naturalisations or acquisition of British citizenship through ancestors, which together add up to $15.7 \%$ of London's population (6\% in E\&W).

With respect to language, $26 \%$ of London's households have at least one person whose main language is not English (8.8\% in E\&W) and in $12.9 \%$ of households no one has English as their main language ( $4.3 \%$ in E\&W). Beyond the Census, other data sources show even higher diversity trends, especially for the younger generations. For example, $40 \%$ of pupils in London schools speak a language at home other than English, covering a total of 322 languages (Von Ahn et al, 2010). If these large shares of the population retain their 'main languages', as well as learning English, London will indeed consolidate its role as a language hub in the world over the coming decades.

In terms of religious beliefs, Londoners are actually more religious than the rest of the country, since the percentage of people who declare 'no religion' is $20.7 \%$ compared to $25.1 \%$ in E\&W. However, the share of Londoners who consider themselves Christian is just $48.4 \%$, while it is $59.3 \%$ in E\&W. Hence, a higher share of Non-Christian religions also indicates a much more 
diverse religious distribution. In descending frequency these are: Muslim (12.4\%), Hindu (5\%), Jewish (1.8\%), Sikh (1.5\%), and Buddhist (1\%), while others are below $1 \%$ of the population. Of course the Christian label disguises a broad range of independent denominations that are not recorded separately in the Census (Anglican, Catholic, Orthodox, Evangelist and many others).

These broad-brush figures do not, however, reflect the nuanced and complex diversity of London's population. Beneath each of these major Census categories hides a range of more subtle differences, subgroups, geographies, identities, 'write-in' labels, and so on, most of which will only be available for research within the next years. Furthermore, when these ten variables can be cross-tabulated, between themselves or with other socioeconomic variables, a myriad of categories will allow researchers to study not only the characteristics of London's strikingly diverse population, but more importantly, to analyse which outcomes actually matter for such population sub-groups, establish temporal trends, and isolate potential sources of discrimination and disadvantage.

Looking into the future towards the 2062 horizon, what it is almost certain is that the ethnocultural diversity of London's population is set to increase. As a result of inter-mixing and cross-fertilization between cultures, languages, nationalities, religions, identities, geographical origins and so on, London's population will probably become one of the most heterogeneous cities in Europe. Furthermore, the unproblematic and clear-cut nature of the current Census categories will almost certainly look naïve in fifty years' time. Perhaps the failed prediction made in the 1920s by sociologist Max Webber, who stated that 'primordial phenomena' such as ethnicity and nationalism would decline in importance and eventually vanish as a result of modernisation, industrialisation and individualism, will finally become true in the London of 2062 .

\section{Conclusion}

How will London's population look in 2062? It will certainly look larger, older and more diverse than it is today. In this chapter, we have presented a range of evidence and broad trends, which together explain the dynamics that will in turn determine London's future population. This exercise has indeed cast more questions than can be tackled in this short essay. Let this conclusion then be a wrap-up of intriguing questions and open-ended predictions that relate to other chapters in this book.

Will London be able to cope with the predicted increases in its population size? How and where will the jobs and houses required be created? The only option will be to increase population density in most parts of the city, a trend set since 1991. But when will the city reach its limit on infilling, retrofitting and recycling of brownfield sites? When will it be considered appropriate to demolish vast swaths of derelict Victorian housing stock to start building up a more compact and affordable city? This will surely bring political turmoil and expose London's stark inequalities between boroughs and neighbourhoods.

Despite physical constraints, the most important policy interventions will be those aimed at maintaining the socioeconomic and cultural factors that make London attractive to youths around the world today, as well as improving the environmental and economic constraints that push older people away. Only a vibrant, sustainable and liveable London will be able to keep its central role in the world city system beyond the mid- $21^{\text {st }}$ century.

London's population will look significantly different in 2062. It will be much older and much more ethnically diverse. The predominant ethnic group will be those with mixed heritage, for whom notions of identity according to a single national, religious or linguistic origin will seem remotely distant. As a result, it will also look extremely different to most of the rest of the UK, with important political consequences; perhaps a different migration regime could be applied to 
London independent of the rest of the UK. This could for example open up the city to world migrants while implementing tele-surveillance measures to prevent residence elsewhere in the country. More likely, greater political powers will be secured for London's regional government, who will finally manage to overhaul its deteriorating public infrastructure (transport, healthcare and schools) and prioritise building much higher residential buildings, over the decisions of individual local authorities and the interest of 'NIMBY' lobby groups. Against common perceptions today, such a dense and fluid city will be loved not only by city youngsters and the wealthy, but also by an aging majority that will not feel the need to run away from urban life when they have children; will have more than one place they call home; and almost certainly will never be able to afford full retirement.

\section{References}

Atkinson S. 2006. Health inequalities in London: where are we now? Health in London - Looking back, looking forward. Available from: http://www.london.gov.uk/lhc/docs/publications/ healthinlondon/2006/Section02.pdf. [Accessed 16 August 2013]

Baker A, Fitzpatrick J, Jacobson B. 2012. Capital Concerns: Comparing London's health challenges with England's largest cities. Available from: http://www.lho.org.uk/Download/Public/17872/1/Capital ConcernsRevised17.07.12.pdf. [Accessed 16 August 2013]

Bongaarts J, Feeney G. 1998. On the quantum and tempo of fertility. Population and Development Review. 24(2): 271-291. Available from: http://www.jstor.org/stable/10.2307/2807974. [Accessed 20 November 2012]

Cheshire J. 2012. Featured graphic: Lives on the line: mapping life expectancy along the London Tube network . Environment and Planning. (A)44: 1525-1528. Available from: http://www. envplan.com/abstract.cgi?id=a45341. [Accessed 15 November 2012]

Coleman DA, Dubuc S. 2010. The fertility of ethnic minorities in the UK, 1960s-2006. Population studies. 64: 19-41. Available from: http://dx.doi.org/10.1080/00324720903391201. [Accessed 15 November 2012]

Graunt J. Natural and Political Observation on the Bills of Mortality [Internet]. 1665. Society R, editor. Available from: http://scholar.google.co.uk/scholar?q=graunt+bills+of+mortality\&btn $\mathrm{G}=\& \mathrm{hl}=$ en\&as_sdt $=0,5 \# 3$. [Accessed 20 November 2012]

Greater London Authority. 2011. Birth and Death Rates, Ward. Available from: http://data.london.gov.uk/datastore/package/birth-and-death-rates-ward. [Accessed 16 August 2013]

Greater London Authority. 2012. Births and Fertility Rates, Borough. Available from: http://data. london.gov.uk/datastore/package/births-and-fertility-rates-borough. [Accessed 16 August 2013]

Greater London Authority. 2012. Population Projections to 2041 for London Boroughs by single year of age and gender using the Strategic Housing and Land Availability Assessment (SHLAA) housing data. Available from: http://data.london.gov.uk/datastore/package/gla-population-projections-2012-round-shlaa-borough-sya. [Accessed 16 August 2013]

Greater London Authority Intelligence Unit. 2012 (October). Migration Indicators Intelligence Update 24-2012. Available from: http://data.london.gov.uk/datastorefiles/documents/update_24_2012.pdf. [Accessed 16 August 2013]

Mateos P. 2014. The international comparability of ethnicity classifications and its consequences for segregation Studies. In: Lloyd C, Shuttleworth I, Wong D, (eds.). Social-Spatial Segregation: Concepts, Processes and Outcomes. Bristol: Policy Press. (In press)

Office for National Statistics. 2011 (19 October). Life expectancy at birth and at age 65 by local areas in the United Kingdom, 2004-06 to 2008-10. Available from: http://www.ons.gov.uk/ons/publications/re-reference-tables.html?edition=tcm:77-223356. [Accessed 16 August 2013] 
Office for National Statistics. 2012. 2011 Census, Key Statistics for Local Authorities in England and Wales. Available from: http://www.ons.gov.uk/ons/publications/re-reference-tables.htm 1 ? newquery $=*$ \&newoffset $=25$ \&pageSize $=25 \&$ edition $=\mathrm{tcm}: 77-286262$. [Accessed 16 August 2013]

Von Ahn M, Lupton R, Greenwood C, Wiggins D, Ahn M Von. 2010. Languages, ethnicity, and education in London. Available from: http://repec.ioe.ac.uk/REPEc/pdf/qsswp1012.pdf. [Accessed 16 August 2013] 


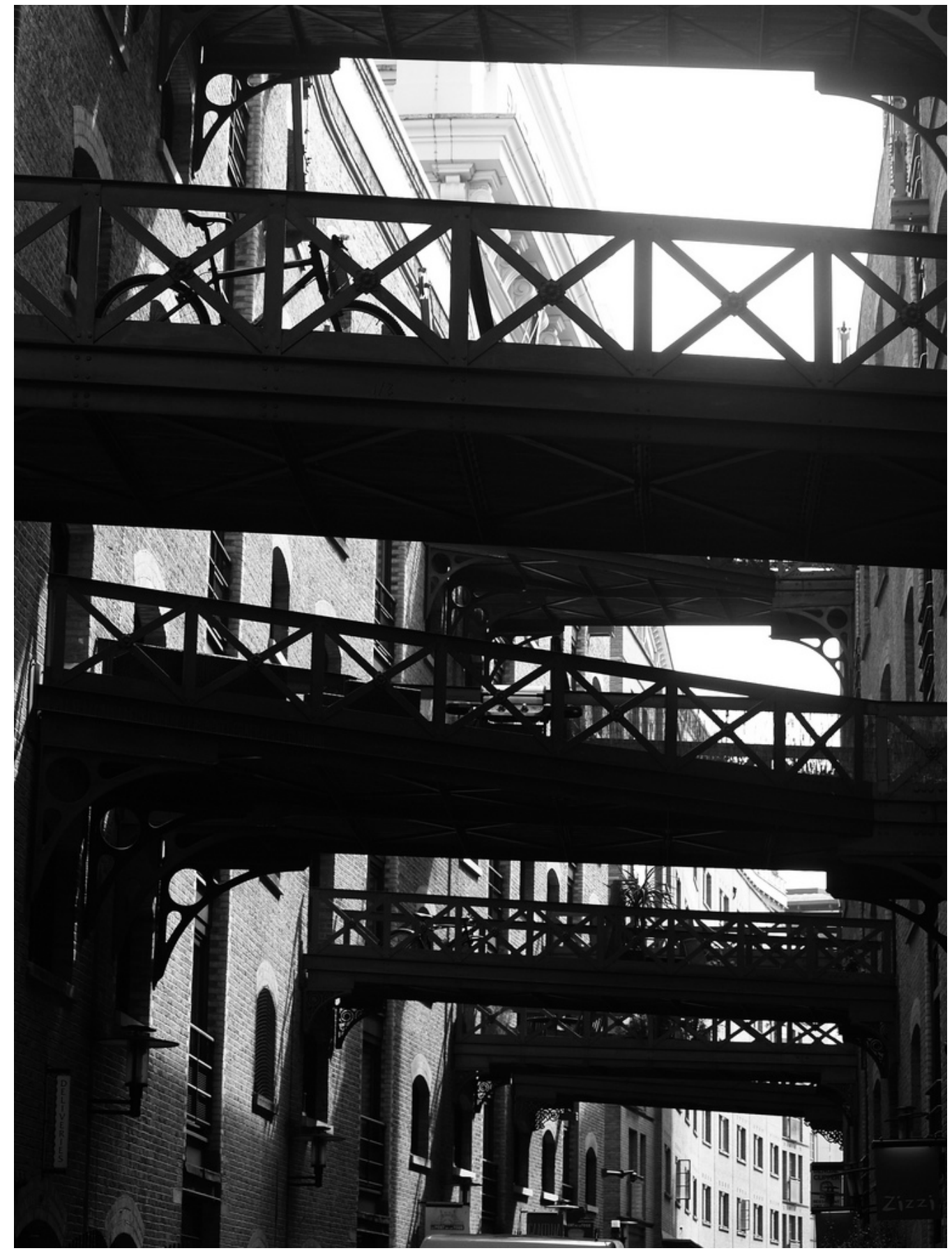

